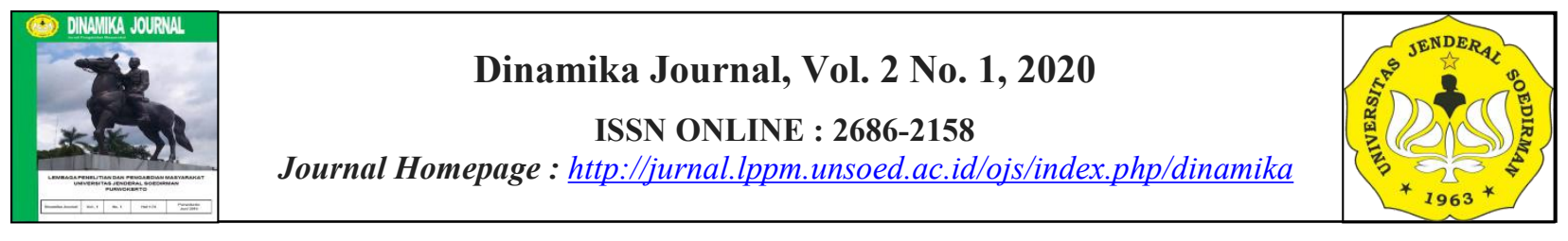

\title{
PARTISIPASI MASYARAKAT DALAM PERENCANAAN RUANG TERBUKA HIJAU DI KELURAHAN BUKIT TUNGGAL KOTA PALANGKA RAYA
}

\author{
Waluyo Nuswantoro ${ }^{1}$, Noor Hamidah ${ }^{2 *}$, Tatau Wijaya Garib ${ }^{2}$, Mahdi Santoso ${ }^{3}$ \\ ${ }^{1}$ Staf Pengajar Prodi Teknik Sipil, Fakultas Teknik, Universitas Palangka Raya, Indonesia \\ ${ }^{2}$ Staf Pengajar Prodi Arsitektur, Fakultas Teknik, Universitas Palangka Raya, Indonesia \\ ${ }^{3}$ Staf Pengajar Prodi Kehutanan, Fakultas Pertanian, Universitas Palangka Raya, Indonesia \\ *Corresponding author : nhamidah04@gmail.com
}

Received 20 January 2020; Accepted 25 February 2020; Available online 28 February 2020

\begin{abstract}
Abstrak
Ruang Terbuka Hijau (RTH) dan taman merupakan sistem keseimbangan antara alam dan manusia pada kawasan terbangun. Konsep penataan RTH dan taman merupakan penyeimbang semakin berkurang ruang terbuka, dan meningkatnya kawasan terbangun. Untuk memperbaiki keseimbangan lingkungan dan kawasan terbangun, RTH pada kawasan terbangun khususnya permukiman perlu dikembalikan fungsinya agar kedua sistem keseimbangan berperan optimal. Penataan taman dan RTH merupakan respon terhadap kebutuhan lansekap pada suatu kawasan permukiman dan wilayah perkotaan. Kebutuhan penataan RTH dan taman secara ideal merupakan keterpaduan aspek ekologi, sosial, dan ekonomi wilayah. Proposal pengabdian masyarakat bertujuan menunjukkan peran partisipasi masyarakat dalam pemanfaatan kebutuhan taman dan RTH pada suatu kawasan permukiman untuk kelestarian ekologi, ekonomi dan sosial di masa depan. Usulan pengabdian masyarakat melibatkan partisipasi masyarakat dalam penataan RTH dan taman sebagai ruang terbuka di kawasan perumahan di Kelurahan Bukit Tunggal, Kecamatan Jekan Raya, Kota Palangka Raya. Metode adalah kualitatif fokus pada amatan partisipasi masyarakat mulai tahap persiapan, pelaksanaan dan pasca pelaksanaan implementasi konsep penataan RTH dan taman penanaman pohon dan penataan taman di perumahan Kelurahan Bukit Tunggal secara terpadu sesuai kebutuhan ruang terbuka untuk kegiatan masyarakat dan pelestarian lingkungan.
\end{abstract}

Kata Kunci: Partisipasi masyarakat, konsep Ruang Terbuka Hijau (RTH) dan taman, Perumahan, Kelurahan Bukit Tunggal 


\section{Abstract}

Green Open Space and parks are a balance system between nature and humans in the built area. The concept of green space and parks is a balancing of decreasing open space, and increasing the area built. To improve the balance of the environment and built area, green space in the built area, especially settlements, needs to be restored in order for the two systems to play an optimal role. Parks and green space is a response to the needs of the landscape in a residential area and urban areas. The need for green space and parks is ideally an integrated ecological, social, and economic aspects of the urban area. Community participation proposal aims to show the role of community participation in the utilization of the needs of parks and green space in a residential area for ecological, economic and social sustainability in the future. The proposed community service involves community participation in the management of green space and parks as open space in a residential area in Bukit Tunggal Village, Jekan Raya District, Palangka Raya City. The method is a qualitative focus on observing community participation from the preparation, implementation and post-implementation stages of the implementation of the concept of green space and tree planting and garden arrangement in housing of the Bukit Tunggal village in an integrated manner according to the needs of open space for community activities and environmental preservation.

Keywords : community participation, Green Open Space and yard concept, housing, Bukit Tunggal Village

\section{PENDAHULUAN}

Kota Palangka Raya adalah ibukota kota Provinsi Kalimantan Tengah, memiliki bentang lahan yang relative luas, dangan permukiman yang relatif padat pada wilayah kota, terutama permukiman-permukiman lama yang tumbuh secara organik. Permukiman ini tumbuh dan berkembang tanpa sebuah perencanaan tentang pentingnya Ruang Terbuka Hijau (RTH).

Kenyamanan suatu permukiman sebagai tempat tinggal sangat tergantung pada ketersediaan RTH. Keberadaan RTH di lingkungan perumahan dan permukiman selain memiliki nilai estetis juga berfungsi secara ekologi yang sangat bermanfaat bagi semua warga penghuni perumahan dan pemukiman tersebut. RTH yang ada pada awalnya dimanfaatkan untuk menambah keindahan lingkungan.

Salah satu upaya pemerintah adalah dengan adanya kebijakan pengembangan RTH. Sebagaimana diungkapkan dalam Peraturan Menteri Dalam Negeri Nomor 1 Tahun 2007 Tentang Penataan Ruang Terbuka Hijau Kawasan Perkotaan diuraikan tujuan penataan ruang terbuka hijau adalah untuk menjaga keserasian dan keseimbangan ekosistem lingkungan perkotaan, mewujudkan kesimbangan antara lingkungan alam dan lingkungan buatan di perkotaan dan (c.) meningkatkan kualitas lingkungan perkotaan yang sehat, indah, bersih dan nyaman. Serta menurut peraturan menteri pekerjaan umum No.05/PRT/M/2008 bahwa berdasarkan jumlah penduduk pada tingkat Rukun Tetangga (RT) dengan jumlah jiwa 250 memerlukan $250 \mathrm{~m}^{2}$ Lahan terbuka hijau, yang dapat direncanakan ditengah kawasan.

RTH merupakan area memanjang/ jalur dan atau mengelompok, yang penggunannya lebih bersifat terbuka, tempat tumbuh tanaman, baik yang tumbuh tanaman secara alamiah maupun yang secara sengaja ditanam (Permen PU No. 05/PRT/M/2008). Hingga saat ini

\section{W. Nuswantoro. 2020. Partisipasi Masyarakat dalam Perencanaan Ruang Terbuka 9}

Hijau| 
pemanfaatan taman RTH masih belum optimal sesuai dengan harapan yakni terwujudnya ruang yang nyaman, produktif dan berkelanjutan.

Keberadaan RTH sangat berperan dalam memperbaiki kualitas hidup masyarakat. Jika dipandang dari fungsinya, maka ruang terbuka hijau dapat dimanfaatkan sebagai ruang publik atau ruang tempat berinteraksi manusia, ruang publik berkembang sejalan dengan kebutuhan manusia dalam melakukan kegiatan bersama baik berkaitan dengan sosial, ekonomi, dan budaya (Darmawan,2006), Nilai-nilai yang terkandung dalam RTH meliputi nilai ekologis dan alam, nilai psikologis, nilai sosial-budaya serta nilai estetika. Nilai ekologis dari RTH adalah sebagai tempat yang menyediakan udara segar, menyerap gas karbondioksida $\left(\mathrm{CO}^{2}\right)$, menahan angin dan dapat mengurangi tingkat kebisingan yang disebabkan oleh kendaraan ataupun sumber lainnya. Wijanarko (2006)

Nilai psikologis dari RTH adalah sebagai tempat berkumpul keluarga, tempat bermain anak-anak, serta dapat dijadikan sebagai tempat untuk melepaskan lelah atau stress. Nilai sosialbudaya yang terkandung dalam RTH adalah sebagai tempat atau ruang untuk interaksi sosial antar masyarakat sehingga nilai sosial dapat tumbuh dan berkembang pada RTH.

Ruang terbuka hijau merupakan pertemuan antara sistem alam dan manusia dalam lingkungan perkotaan (Astari, 2012). Ruang terbuka hijau merupakan area memanjang dan mengelompok yang penggunaanya lebih bersifat terbuka, tempat tumbuh tanaman baik yang tumbuh secara alamiah maupun sengaja di tanam (UU No.26/2007). Ruang terbuka hijau kota merupakan bagian dari penataan ruang suatu kawasan perkotaan yang diisi oleh tumbuhan dan tanaman guna mendukung manfaat ekologi, sosial, budaya, ekonomi, dan estetika, serta berfungsi sebagai kawasan lindung. (Shani,2015). RTH dibangun dari kumpulan tumbuhan dan tanaman atau vegetasi yang telah diseleksi dan disesuaikan dengan lokasi serta rencana dan rancangan peruntukkannya. Lokasi yang berbeda dan akan memiliki permasalahan yang juga berbeda yang selanjutnya berkonsekuensi pada rencana dan rancangan RTH yang berbeda.

Peran serta masyarakat dalam pengelolaan RTH merupakan salah satu faktor penting guna mengeliminasi, setidaknya mengurangi potensi timbulnya konflik kepentingan dalam pemanfaatan ruang. Tujuan akhir penataan ruang, adalah untuk kepentingan seluruh lapisan masyarakat. (Hardjasoemantri, 1991) mengatakan apabila tindakan-tindakan diambil untuk kepentingan masyarakat dan apabila masyarakat diharapkan untuk menerima dan patuh pada tindakan tersebut, maka masyarakat harus diberi kesempatan untuk mengembangkan dan mengutarakan pendapatnya.

Peran serta masyarakat dalam pengelolaan Ruang Terbuka Hijau merupakan salah satu faktor pentingnya guna mengurangi potensi timbulnya konflik kepentingan dalam pemanfaatan ruang. (Nadia, 2015) Peran serta masyarakat dapat dipandang sebagai suatu upaya untuk membantu negara dan lembaga lembaganya guna melaksanakan tugas dengan cara yang lebih dapat diterima guna melaksanakan tugas dengan cara yang dapat diterima. Banyak sekali Manfaat yang diperoleh bagi kehidupan masyarakat yaitu dapat menjamin keberlangsungan hidup yang bersih, sehat, nyaman dan indahkeberadaan mereka juga sangat penting khususnya dalam menjaga sirkulasi udara dan ketersediaan air selain itu RTH dapat menjadi pilihan lokasi untuk sekedar melepas kepenatan diakhir pekan.

Melihat fungsi dari ruang terbuka hijau, maka pengelolaannya tidak dapat dipisahkan dari masyarakat. Hal inilah sangat perlu keterlibatan dan peran serta masyarakat dalam merencanakan, membangun bersama pengelolaan RTH dan bersinergi dengan perguruan tinggi dan pemerintah kelurahan.

10 Dinamika Journal Vol. 2 No. 1, Februari $2020: 8$ - 18 
Dasar pertimbangan yang melatarbelakangi usulan pengabdian masyarakat antara lain terbatasnya ketersediaan Ruang Terbuka Hijau di kawasan permukiman lama, mengindikasikan kondisi kawasan di Kelurahan Bukit Tunggal terutama kawasan permukiman perlu ditanami vegetasi sebagai pelindung dan estetika, serta penahan air hujan.

\section{METODE}

Pengabdian masayrakat ini menggunakan metode kualitatif dengan studi kasus pada potensi penataan RTH di Permukiman Jalan Bandeng V Kelurahan Bukit Tunggal, Kecamatan Jekan Raya, Kota Palangka Raya seperti tertera pada Gambar 1. Pemilihan lokasi dipilih dengan pertimbangan antara lain: (1) Lokasi perumahan dan permukiman Kelurahan Bukit Tunggal, Kecamatan Jekan Raya, Kota Palangka Raya dipilih karena belum tersedia RTH dan taman bagi fasilitas permukiman. (2) potensi kesadaran masyarakat pada lingkungan tentang perlunya penghijauan dan ruang hijau, hal ini terlihat adanya tanaman bunga dan tanaman keluarga yang telah dibudidayakan masyarakat di lingkungan huniannya. Data primer diperoleh melalui pengambilan sampel lokasi dengan alat Drone dan pengamatan langsung potensi eksisting di Perumahan Jalan Bandeng V. Data sekunder, diperoleh melalui berbagai literatur serta kelengkapan informasi yang di butuhkan sebagai bagian kajian pustaka. Data sekunder diobservasi dengan data citra yang terdapat di google Earth sebagai data penunjang. Kegiatan pengabdian masyarakat dilakukan dengan informan masyarakat di Permukiman Jalan Bandeng $\mathrm{V}$ mulai dari usulan hingga pelaksanaan, dilakukan melalui partisipasi masyarakat. Data digunakan pada kegiatan pengabdian adalah data primer dan data sekunder.

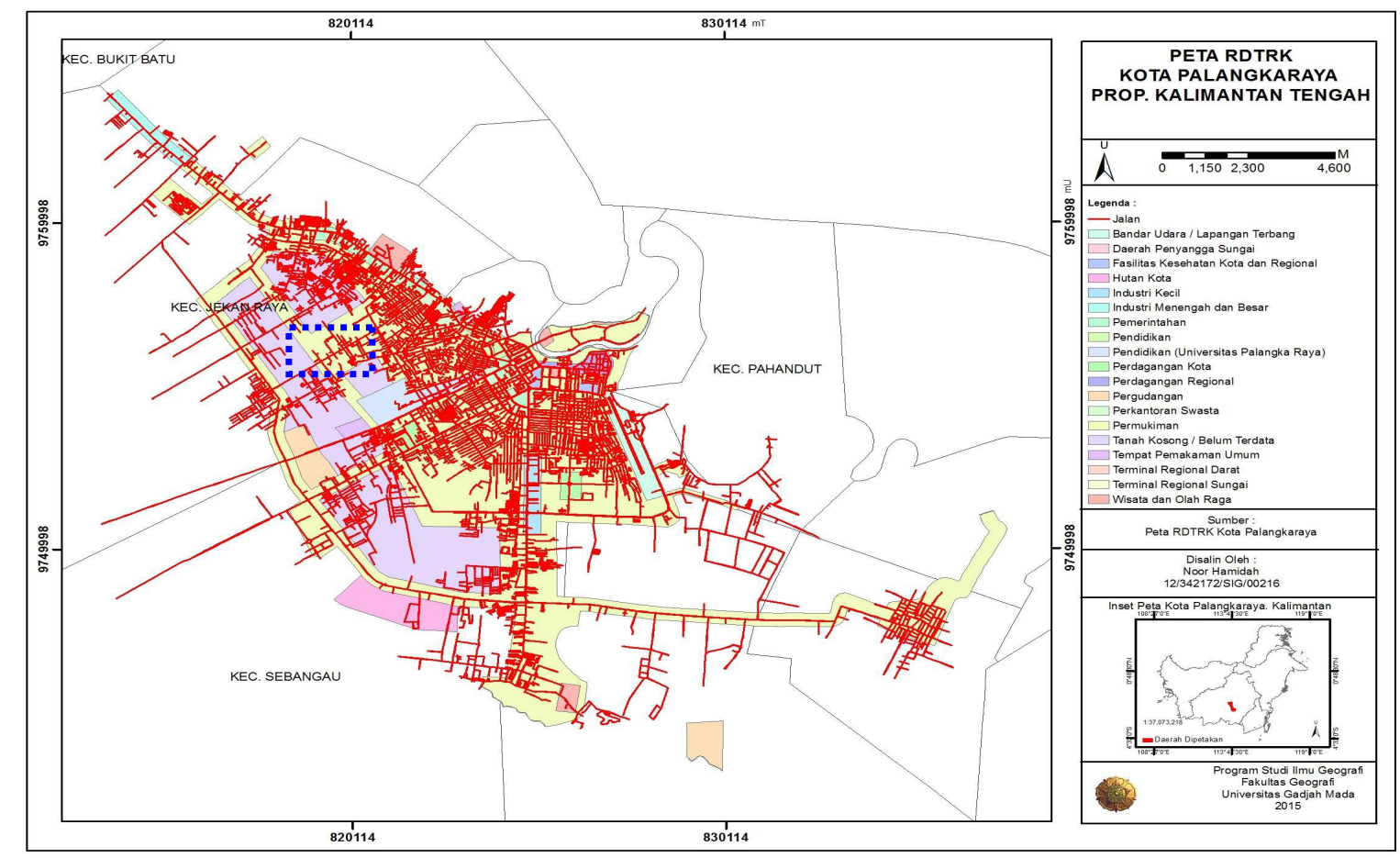

Gambar 1 Lokasi Kegiatan Pengabdian di Kelurahan Bukit Tunggal, Kecamatan Jekan Raya, Kota Palangka Raya (Sumber: Citra Quickbird, 2017)

\section{W. Nuswantoro. 2020. Partisipasi Masyarakat dalam Perencanaan Ruang Terbuka 11} Hijau| 
Tahapan kegiatan pengabdian masyarakat adalah sebagai berikut: (1) tahap persiapan, (2) tahap pelaksanaan, dan (3) tahap pasca pelaksanaan. Pertama, tahap persiapan yaitu mengidentifikasi berbagai potensi yang dimiliki kawasan permukiman di Kelurahan Bukit Tunggal terkait lokasi, peran masyarakat, kepedulian masyarakat terhadap lingkungan. Hasil identifikasi potensi kegiatan melakukan pengabdian disampaikan ke Pemerintah Kelurahan Bukit Tunggal untuk proses ijin melakukan kegiatan pengabdian masyarakat. Tahap persiapan meliputi pengumpulan data literatur terkait pada kebutuhan dan pemanfaatan fungsi Ruang Terbuka Hijau di Perumahan Jalan Bandeng V Kelurahan Bukit Tunggal. Kedua, tahap pelaksanaan meliputi wawancara terbagi dua antara lain: (1) wawancara dengan warga Perumahan Jalan Bandeng V dengan menggali informasi dan ide keinginan masyarakat terhadap kebutuhan RTH. (2) Wawancara mendalam ke Pemerintah di tingkat Kelurahan Bukit Tunggal, Ketua RT-02 RW-VIII Jalan Bandeng V, dan Lurah Bukit Tunggal. Ketiga, tahap pasca pelaksanaan pengabdian yaitu pemetaan titik-titik potensial untuk konsep perencanaan Ruang Terbuka Hijau pada permukiman Jalan Bandeng V Kelurahan Bukit Tunggal dan analisa perencanaan RTH.

\section{HASIL DAN PEMBAHASAN}

Pelaksanaan kegiatan :

1. Audensi dengan Lurah Bukit Tunggal :

Sebelum melaknakan kegiatan tim pengabdian masyarakat dari Fakultas Teknik (FT) Universitas Palangka Raya (UPR) melaksanakan audensi dengan jajaran Pemerintah Kelurahan Bukit Tunggal seperti tertera di Gambar 2. Pemerintah Kelurahan Bukit Tunggal memberikan informasi mengenai karakteristik masyarakat, kebutuhan masyarakat, partisipasi masyarakat, program Kelurahan Bukit Tunggal dalam hal kegiatan penghijauan, sehingga dapat bersama bersinergi antara warga, pemerintah kelurahan dan Perguruan Tinggi dalam hal program Pengabdian pada masyarakat sehingga dapat tercapai tujuan Bersama.

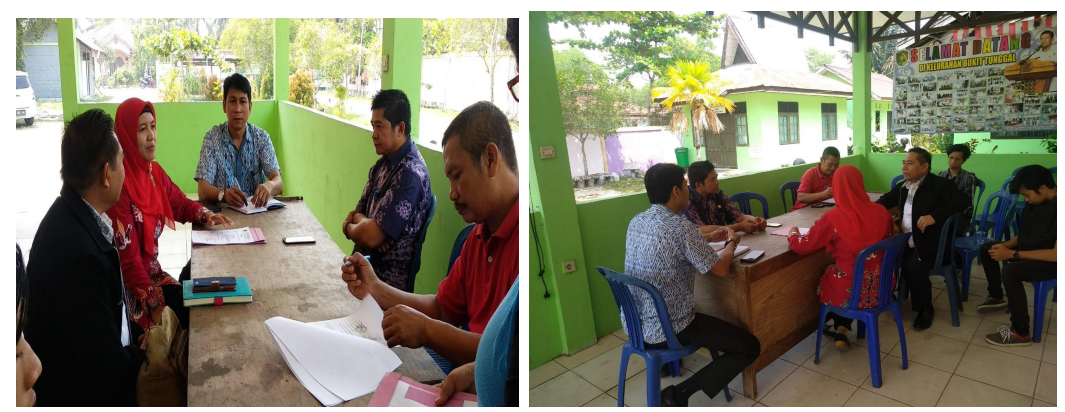

Gambar 2. Foto kegiatan audensi dengan pemerintah kelurahan

(Sumber: Dokumentasi Tim Pengabdian FT, UPR 2019)

2. Survai Lapangan awal :

Berdasarkan informasi dari Pihak Kelurahan Bukit Tunggal dilakukan survai awal kegiatan Pengabdian pada masyarakat seperti tertera di Gambar 3. Kegiatan survei bersama tim pengabdian FT UPR didampingi oleh lurah, Babinsa, Ketua RT dan warga Jalan Bandeng V sebagai lokasi yang diarahkan oleh pihak Kelurahan Bukit Tunggal. 

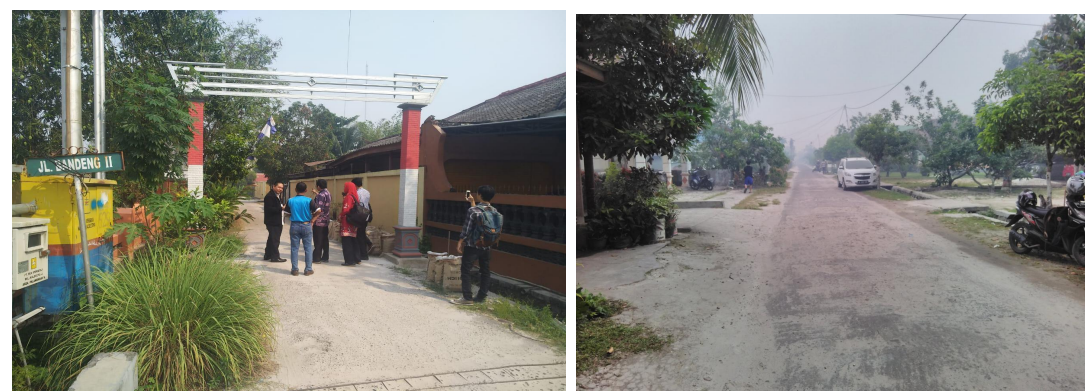

Gambar 3. Foto kegiatan Survai Awala Pada Jalan Bandeng V (Sumber: Dokumentasi Tim Pengabdian FT UPR 2019)

3. Survai Ianjutan :

Pada kegiatan Survai lanjutan ini dilakukan pada saat musim kemarau, dilakukan bersama pihak kelurahan beserta ketua RT dan warga dengan melakukan pemetaan, pendataaan, inventarisasi vegetasi dan ruang-ruang yang dapat difungsikan sebagai ruang hijau dan tanaman hijau seperti tertera di Gambar 4.
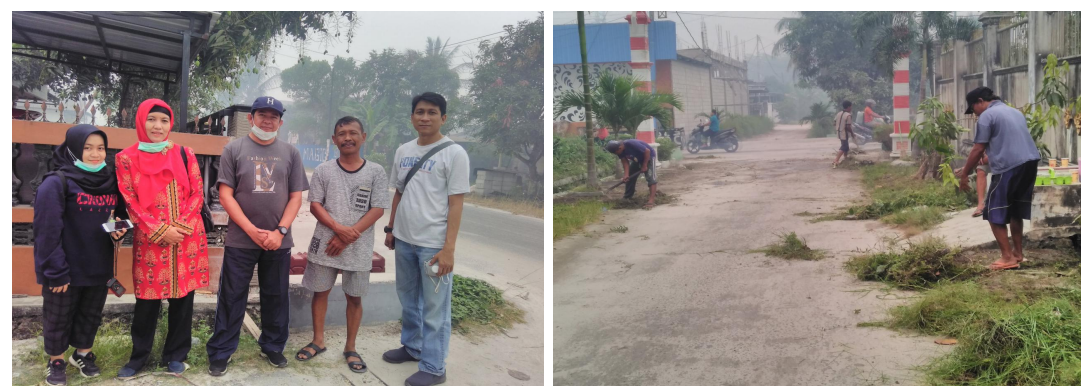

Gambar 4. Foto kegiatan Survai lanjutan Pada Jalan Bandeng II

(Sumber: Dokumentasi Tim Pengabdian FT UPR 2019)

Setelah kegiatan survai dilakukan pengolahan data lapangan, pada Jalan Bandeng V yang dibagi dalam 13 (tiga belas) segmen jalan dengan desain masing-masing segmen mempunyai karakteristik dan tema berbeda, yaitu :

a) Segmen 1: tema taman pergola

b) Segmen 2 sampai segmen 10: tema vegetasi budidaya dan mural

c) Segmen 11 sampai segmen 12 : tema tanaman pot

d) Segmen 13: tema taman pergola

Hasil pengolahan tiap-tiap segmen ini disampaikan pada pertemuan dengan masyarakat untuk mendapatkan masukan, pada ekspos lanjutan. 


\section{SITE PLAN}

\section{JI. Bandeng V, Kel. Bukit Tunggal}

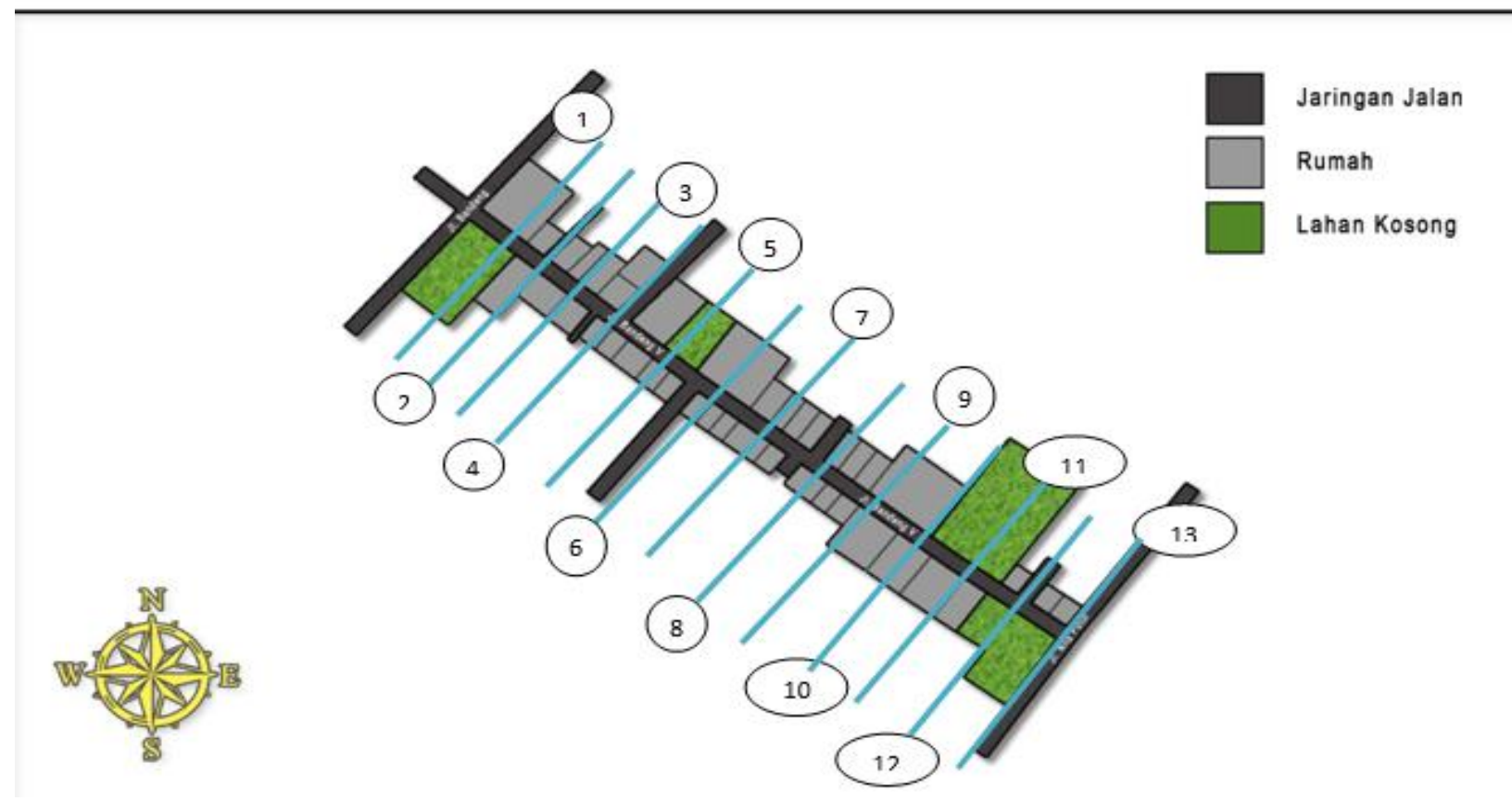

Gambar 5. Peta 13 (tiga belas) segmen pada Jalan Bandeng V (Sumber: Dokumentasi Tim Pengabdian FT UPR 2019)

4. Ekspos pertama

Ekspos pertama adalah paparan potensi Ruang Terbuka Hijau ke masyarakat di Perumahan Jalan Bandeng V Kelurahan Bukit Tunggal seperti tertera di Gambar 6. Hasil ekpos pertama diperoleh masukan atas keinginan masyarakat terhadap masing-masing segmen. Implemantasi keinginan tiap masyarakat di Perumahan Jalan Bandeng V dimasukkan dalam konsep dari masing-masing segmen.
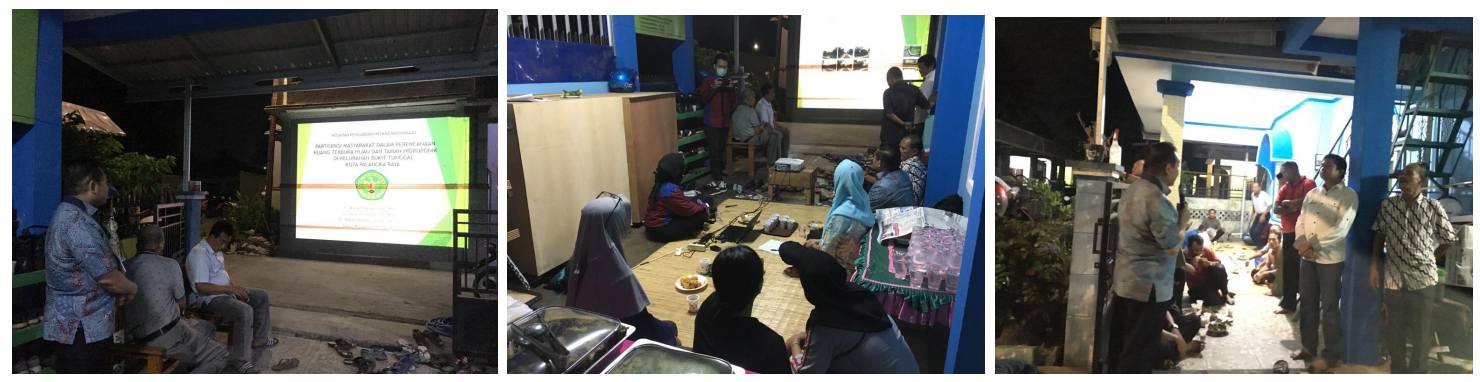

Gambar 6. Foto kegiatan ekspos awal Jalan Bandeng II

(Sumber: Dokumentasi Tim Pengabdian FT UPR 2019)

Hasil konsep desain diperoleh dari keinginan masyarakat Perumahan Jalan Bandeng V dalam paparan ekspos pertama. Tema dibuat per segmen mengenai kebutuhan Ruang Terbuka Hijau, vegetasi yang digunakan dan kemudahan perawatan vegetasi. Usulan vegetasi bermanfaat bagi 
masyarakat di Perumahan Jalan Bandeng V, yang diimplementasikan ke dalam desain 3D (tiga dimensi). Konsep desain dibagi dalam 13 (tiga belas) segmen jalan dengan karakteristik dan tema berbeda, antara lain:

a) Segmen 1: tema taman pergola seperti tertera di Gambar 7

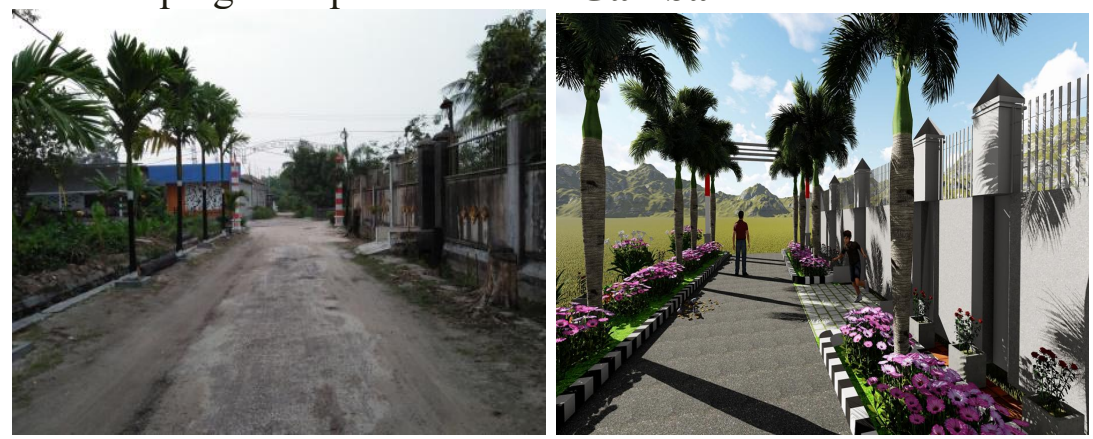

Gambar 7. Foto eksisting dan rencana Segmen 1 (Satu) dengan tema taman pergola (Sumber:

Dokumentasi Tim Pengabdian FT UPR 2019)

b) Segmen 2 sampai segmen 10 tema vegetasi budidaya dan mural seperti tertera di Gambar 8
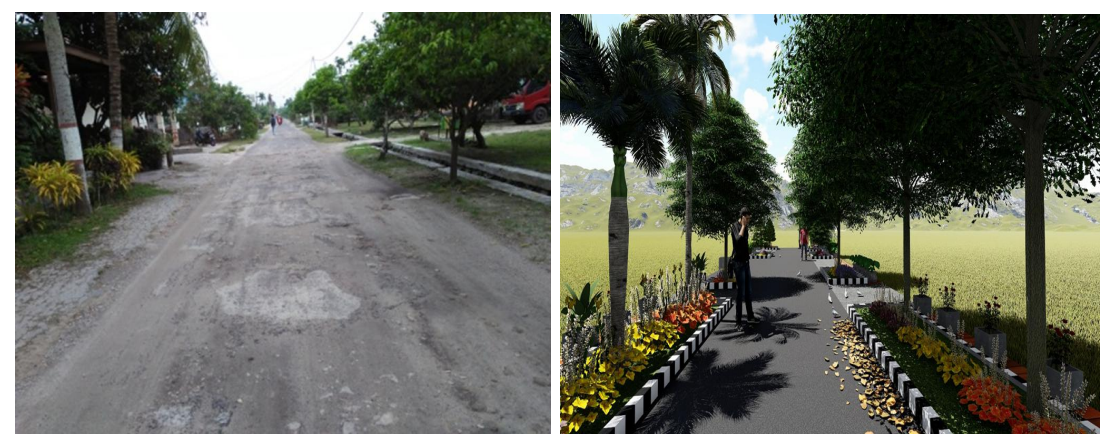

Gambar 8. Foto eksisting dan rencana Segmen 2 sampai segmen 10 tema dengan tema vegetasi budidaya dan mural (Sumber: Dokumentasi Tim Pengabdian FT UPR 2019)

c) Segmen 11 sampai segmen 12 : tema tanaman pot seperti tertera di Gambar 9
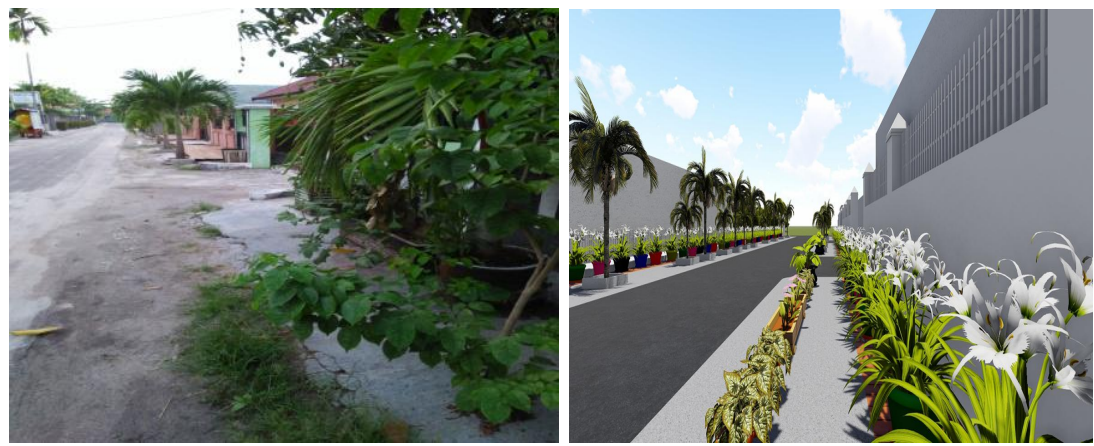

Gambar 9. Foto eksisting dan rencana Segmen 11 sampai Segmen 12 dengan tema tanaman pot (Sumber: Dokumentasi Tim Pengabdian FT UPR 2019) 
d) Segmen 13: tema taman pergola seperti tertera di Gambar 10
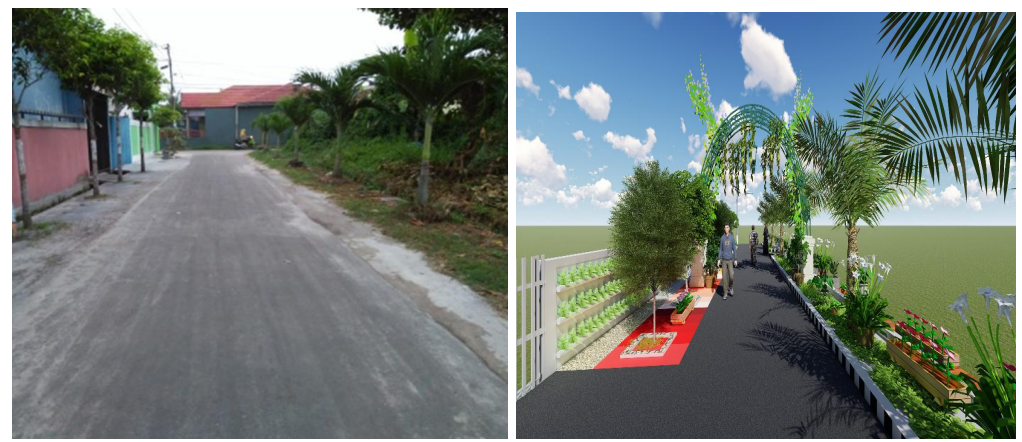

Gambar 10. Foto eksisting dan rencana Segmen 13 (tiga belas) dengan tema taman pergola (Sumber: Dokumentasi Tim Pengabdian FT UPR 2019)

Hasil masukan dari masyarakat pada ekspos pertama pada masing-masing segmen telah dilakukan penyesuaian desain gambar.

5. Ekspos kedua

Selanjutnya dilakukan ekspos presentasi kedua kepada warga masyarakat Jalan Bandeng V, pihak Kelurahan, pihak yang mewakili Kecamatan serta Wakil Walikota Palangka Raya seperti tertera di Gambar 11. Presentasi ini sebagai masukan dan dukungan dari Pemerintah Daerah Kota Palangka Raya dalam rangka dukungan anggaran pada skema pembiayaan dari Pemerintah Daerah, ke Pemerintah Kelurahan, maupun dari Tanggung jawab Sosial Perusahaan atau Corporate Social Responsibility (CSR), sehingga masyarakat Jalan Bandeng $\mathrm{V}$ dapat lebih ringan dalam hal pembiayaan kegiatan Ruang Terbuka Hijau, dengan komitmen akan bersinergi ke semua pihak

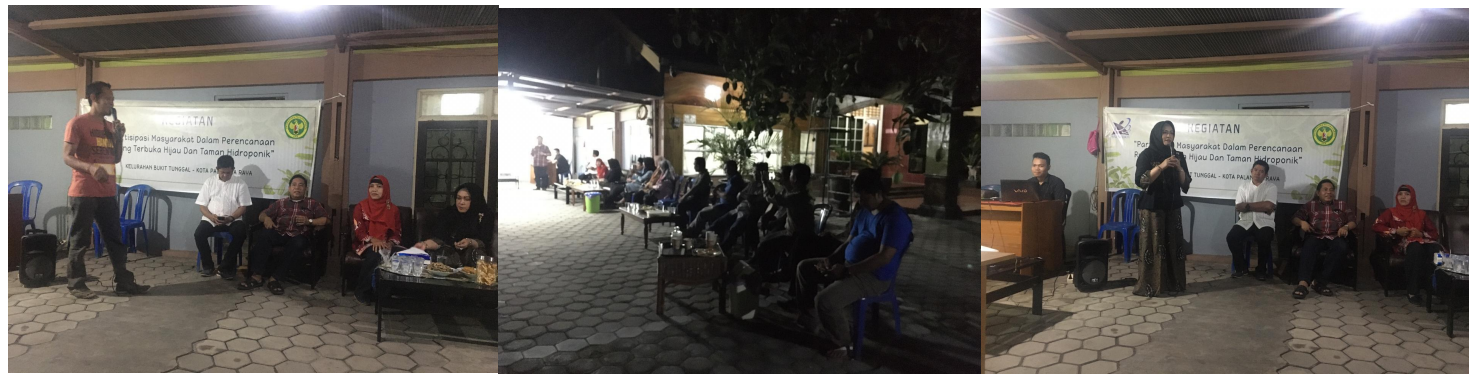

Gambar 11. Ekspos kedua kegiatan dengan warga dan Wakil Walikota Palangka Raya (Sumber: Dokumentasi Tim Pengabdian FT UPR 2019)

Dari hasil ekspos didapatkam masukan-masukan atas rencana skema pembiayaan baik dari Pemerintah Daerah Kota Palangka Raya dari skema CSR. Pembuatan desain per segmen bertujuan masing-masing segmen dapat dilanjutkan dalam Detail Engineering Design (DED) maupun dibuat Rencana Anggaran Biaya (RAB) sehingga dapat diajukan pada instansi maupun perusahaan yang dapat mendukung kegiatan pembangunan RTH dan Taman di perumahan Jalan Bandeng V, Kelurahan Bukit Tunggal. 


\section{KESIMPULAN}

Pada kegiatan Pengabdian pada masyarakat sangat perlu sinergitas antara semua pihak yaitu Pemerintah Derah, Perguruan Tinggi, Pihak Swasta dan Masyarakat dalam diskusi membuat kota ramah dan nyaman untuk ditempati. Potensi Ruang Terbuka Hijau tercipta dari beberapa komponen yang ada diharapkan dapat meningkatkan antara lain: 1) kenyamanan; 2) kualitas hidup; 3) interaksi sosial; 4) meningkatkan kesejahteraan masyarakatnya. Keterlibatan semua pihak perlu dilakukan pendekatan dengan menjadwalkan kegiatan rutin pertemuan masyarakat di Perumahan Bandeng V. Masyarakat diharapkan memiliki kesadaran untuk menjaga dan merawat Ruang Terbuka Hijau karena mendapatkan manfaat langsung untuk kenyamanan. Ruang interaksi warga, meningkatkan kualitas dan kesejahteraan masyarakat.

\section{UCAPAN TERIMAKASIH}

Penulis mengucapkan terima kasih kepada Rektor Universitas Palangka Raya atas kesempatan kepada peneliti untuk memperoleh hibah penelitian DIPA PNBP Tahun 2019 dengan Nomor Kontrak: 042.01.2.400956/2019, tanggal 20 Juni 2019. Terima kasih kepada Lurah Bukit Tunggal, Kecamatan Jekan Raya beserta masyarakat Jalan Bandeng Khusunya J1. Bandeng II Kelurahan Bukit Tunggal Kecamatan Jekan Raya Kota Palangka Raya.

\section{DAFTAR PUSTAKA}

Astari. 2012. Tourism Board: Strategi Promosi Pariwisata Daerah. Putra Media Nusantara. Surabaya.

Carr, S., M. Francis, L. G. Rivlin, A.M. Stone. 1992. Public Space. USA: Cambridge University Press.

Damanik, Janianton dan Weber, Helmut F. 2006. Perencanaan Ekowisata: dari Teori ke Aplikasi De Chaira, Joseph, 1997 Standar perencanaan tapak, Erlangga

Dirawan, D. G. 2003. Analisis Sosio-Ekonomi dalam Pengembangan Ekotourisme pada Kawasan Suakamarga Satwa Mampie Lampoko Bogor: Disertasi IPB

Disbudpar Palangka Raya. 2012. Laporan Akhir Perencanaan Kawasan Ekowisata Sungai Kahayan, Kota Palangka Raya

Dinas Pariwisata Provinsi Kalimantan Tengah, 2011. Pesona Pariwisata Kalimantan Tengah.

Eko Budiharjo, 1997, Tata Ruang Perkotaan, Penerbit Alimni, Bandung.

Elbas Lambertus, Akmad Akya, Bahen Tunika Bahen: Arsitektur Tradisional Daerah Kalimantan Tengah, Departemen Pendidikan dan Kebudayaan Proyek Inventaris dan Dokumentasi Kebudayaan Daerah Jakarta, 1986.

Fandeli, Chafid. 2002. Perencanaan Kepariwisataan Alam. Yogyakarta: Fakultas Kehutanan UGM

Hamidah N., Rijanta, Setiawan, Marfai. 2017. "Kampung” as A Formal and Informal Integration Model (Case: Kampung Pahandut, Central Kalimantan Province, Indonesia. Indonesian Journal of Spatial and Regional Analysis "Forum Geografi". Volume 31, Issue 1, pp. 4355, July 2017.

Hamidah N., Garib T. W., Santoso M., 2018. Pengembangan Kawasan Wisata Di Kelurahan Pahandut Seberang Kota Palangka Raya, Jurnal Perspektif, Volume 13, Nomor 1, halaman 18 - 22, Juli 2018, Jurusan Arsitektur, Fakultas Teknik, Universitas Palangka Raya.

W. Nuswantoro. 2020. Partisipasi Masyarakat dalam Perencanaan Ruang Terbuka 17

Hijau| 
Hamidah N., Garib T. W., Santoso M., 2017. Analisa Penataan Kelurahan Pahandut Seberang Kota Palangka Raya, Jurnal Perspektif, Volume 12, Nomor 2, halaman 26 - 33, Desember 2017, Jurusan Arsitektur, Fakultas Teknik, Universitas Palangka Raya.

Hamidah N., Garib T. W., Santoso M., 2015. Pengelolaan Kawasan Ruang Hijau di DAS Kahayan Kota Palangka Raya, Jurnal Perspektif, Volume 10, Nomor 1, halaman 13 - 25 , Juli 2015, Jurusan Arsitektur, Fakultas Teknik, Universitas Palangka Raya.

Hardjasoemantri koesnadi, 1991. Hukum Perlindungan Lingkungan ; Konservasi Sumber Daya Alam Hayati dan Ekosistemnya. Yogyakarta : Gadjah Mada University Press.

Nadia, Astriani, Peran Masyarakat Dalam Pengelolaan Ruang Terbuka Hijau (RTH) Di Kota Bandung, (Bandung : Universitas Pajajaran Bandung),

Laksono, P.M., dkk., edisi 2006. Pergulatan Identitas Dayak dan Indonesia: Belajar dari Tjilik Riwut. Yogyakarta: Galangpress.

Migang, Rio.S, dkk., 2010. Pariwisata Kalimantan: Pemikiran \& Perjalanan ke Jantung Borneo. Arsimedik Publishing. Jakarta.

Rautner, Mario., dkk. 2005. Borneo: Treasure Island at Risk. WWF Germany.

Roger Trancik, 1986, Figure ground theory, linkage theory and Place Theory

Shani, F Maulana, 2015 , Kajian Ketersediaan Dan Kebutuhan Ruang Terbuka Hijau Kawasan Perkotaan Di Kota Sukabumi, Jurnal Bumi Indonesia

Torre Lazeo,1989, Waterfront Development, Van nostrand Reinhold. New York.

Tafalas, M. 2010. Dampak Pengembangan Ekowisata Terhadap Kehidupan Sosial dan Ekonomi Masyarakat Lokal. Studi Kasus: Ekowisata Bahari Pulau Mansuar, Raja Ampat. Penelitian Pascasarjana (S-2). IPB. Bogor

UNWTO. 2010. Tourism Highlights. www.unwto.org/pub

Wahid, Yunus Pengantar Hukum Tata Ruang, Jakarta: 2014, Prenadamedia Group

Wijanarka., 2006, Desain Tepian Sungai, Penerbit: Ombak, Surabaya.

Wijanarko, Bambang. 2006. Kemungkinan Penerapan CO-Management Dalam Pengelolaan Ruang Terbuka Hijau Di Pantai Utara Kota Surabaya. Tesis. Semarang : Magister Teknik pembangunan Wilayah dan Kota. Universitas Dipenogoro.

18 Dinamika Journal Vol. 2 No. 1, Februari 2020 : 8 - 18 